\title{
Caesarean section among referred and self- referred birthing women: a cohort study from a tertiary hospital, northeastern Tanzania
}

\author{
Ingvil K Sørbye ${ }^{1 *}$, Siri Vangen ${ }^{1,2}$, Olola Oneko ${ }^{3}$, Johanne Sundby ${ }^{4}$ and Per Bergsjø $\varnothing^{2}$
}

\begin{abstract}
Background: The inequity in emergency obstetric care access in Tanzania is unsatisfactory. Despite an existing national obstetric referral system, many birthing women bypass referring facilities and go directly to higher-level care centres. We wanted to compare Caesarean section (CS) rates among women formally referred to a tertiary care centre versus self-referred women, and to assess the effect of referral status on adverse outcomes after CS.

Methods: We used data from 21,011 deliveries, drawn from the birth registry of a tertiary hospital in northeastern Tanzania, during 2000-07. Referral status was categorized as self-referred if the woman had bypassed or not accessed referral, or formally-referred if referred by a health worker. Because CS indications were insufficiently registered, we applied the Ten-Group Classification System to determine the CS rate by obstetric group and referral status. Associations between referral status and adverse outcomes after CS delivery were analysed using multiple regression models. Outcome measures were CS, maternal death, obstetric haemorrhage $\geq 750 \mathrm{~mL}$, postpartum stay $>9$ days, neonatal death, Apgar score $<7$ at 5 min and neonatal ward transfer.

Results: Referral status contributed substantially to the CS rate, which was 55.0\% in formally-referred and 26.9\% in self-referred birthing women. In both groups, term nulliparous singleton cephalic pregnancies and women with previous scar(s) constituted two thirds of CS deliveries. Low Apgar score (adjusted OR 1.42, 95\% Cl 1.09-1.86) and neonatal ward transfer (adjusted OR 1.18, 95\% Cl 1.04-1.35) were significantly associated with formal referral. Early neonatal death rates after CS were 1.6\% in babies of formally-referred versus 1.2\% in babies of self-referred birthing women, a non-significant difference after adjusting for confounding factors (adjusted OR 1.37, 95\% Cl 0.87-2.16). Absolute neonatal death rates were $>2 \%$ after CS in breech, multiple gestation and preterm deliveries in both referral groups.

Conclusions: Women referred for delivery had higher CS rates and poorer neonatal outcomes, suggesting that the formal referral system successfully identifies high-risk birth, although low volume suggests underutilization. High absolute rates of post-CS adverse outcomes among breech, multiple gestation and preterm deliveries suggest the need to target self-referred birthing women for earlier professional intrapartum care.
\end{abstract}

\section{Background}

Progress towards Millennium Development Goals (MDGs) 4 and 5, to reduce child and maternal mortality and morbidity, is unsatisfactory in most sub-Saharan countries $[1,2]$. It is widely acknowledged that improved and equal access to emergency obstetric care is crucial in addressing survival [3-5]. As is the case for several

\footnotetext{
* Correspondence: ingvil.krarup.sorbye@rikshospitalet.no

${ }^{1}$ National Resource Centre for Women's Health, Department of Obstetrics and Gynaecology, Oslo University Hospital HF, Rikshospitalet, Oslo, Norway Full list of author information is available at the end of the article
}

sub-Saharan countries, Tanzania has had a constant low national average Caesarean section (CS) rate (3\%) since 1999 [6]. This is below the minimum recommended level, reflecting considerable unmet needs for emergency obstetric care [7-9]. Where a large proportion of births take place outside facilities, an effective referral system is necessary, but not sufficient, to achieve equitable access to emergency obstetric care. Normal delivery services are available in $74 \%$ of health facilities in Tanzania, but only $40 \%$ of facilities provide emergency transport to a referral site where comprehensive emergency obstetric

\section{Biomed Central}


care is offered [10]. Although a national referral system with standard criteria for referral of obstetric complications in women in need of hospital delivery is implemented in Tanzania, bypass of referring facilities ('selfreferral') is a familiar phenomenon [11,12].

In the Kilimanjaro Region in the Northern Zone of Tanzania, the CS rate is 7.2\% [6]. Although more than double the national average, the rate does not disclose whether or not the interventions target those who need them and is no guarantee for equity in access to care [13]. Our study was initiated by the findings that the zonal tertiary hospital, Kilimanjaro Christian Medical Centre (KCMC), had a high CS rate of 33\% during the period 2000-07, together with a high proportion of self-referred birthing women. We wanted to compare CS rates among women formally referred for hospital delivery versus self-referred women. A secondary objective was to assess risk of adverse maternal and neonatal outcomes after CS according to referral status. As indications for CS were insufficiently registered, we applied the Ten-Group Classification System [14] to identify risk groups for targeted intervention.

\section{Methods}

\section{Study setting}

We used data from the medical birth registry at the zonal referral hospital KCMC in northeastern Tanzania to perform a cohort study of 21,011 births and 21,614 newborns from the period January $1^{\text {st }} 2000$ to August $31^{\text {st }} 2007$. Births with birth weight $\geq 500 \mathrm{~g}$ or gestational age $\geq 22$ weeks were included. The birth registry, which has been described in detail elsewhere [15], systematically and prospectively collects information on sociodemographic and basic obstetric indicators, as well as information on delivery modes and pregnancy outcomes. Trained midwives conduct interviews and collect case record information in the days after birth, with a response rate of $>98 \%$. The facility runs as a private/public partnership. The obstetric department receives patients from the local uptake area (Moshi town) in addition to referrals from a larger geographical area. CS is almost exclusively performed at hospitals in Tanzania [10], and most CS deliveries for women living in urban Moshi (Moshi District Council) are carried out at the facility. In Kilimanjaro Region, $70 \%$ of births take place at a health facility [6], and in Moshi, 92\% deliver at a facility [16]. The site of the present study (a tertiary birth centre) is thus not a population-representative sample, as many women deliver at lower level facilities in the area or at home. There is potential selection towards financially better off women due to the cost-sharing policy gradually introduced for maternity services at KCMC from 2005 onwards. For a normal delivery, out-of-pocket costs are in the range of 5,000-15,000 TZS (5-15 USD), while a CS has added minimum costs of 25,000-30,000 TZS (25-30 USD) [17]. In comparison, $88.5 \%$ of the population in
Tanzania lived on less than USD 1.25 a day in 2000 [18]. The national health policy provides exemptions for the poor, but these are incompletely implemented.

\section{The Ten-Group Classification System for Caesarean deliveries}

The Ten-Group Classification System for CS deliveries provides a standardised framework for monitoring of obstetric practice for individual institutions. The classification is meant both for application to existing birth data, and for use as a prospective tool to identify at-risk groups. Contrary to previous classification systems for CS, the Ten-Group Classification System is independent of the medical indication(s) for a CS. Using this standardised classification it is easy to identify which groups are the primary contributors to the overall CS rate, as well as determine CS rates and pregnancy outcomes within the different obstetric groups. CS rates in each group and contributions to overall rate can be compared across different facilities and between different levels of facilities. It has been applied internationally in highresource settings among equivalent sub-populations $[14,19,20]$.

We applied the Ten-Group Classification System to existing birth data drawn from the medical birth registry at KCMC. We classified women into ten mutually exclusive groups based on four obstetric characteristics: previous obstetric history, gestational age, category of pregnancy and course of pregnancy [14].

\section{Demographic and medical variables}

The essential information needed to apply the Ten-Group Classification System was available in the registry. We defined the following variables: parity coded as 0 or $\geq 1$; multiple gestation coded as yes or no; presentation (at delivery) coded as cephalic, breech or abnormal; previous CS coded as yes or no; induction of labour coded as yes or no; CS coded as elective or non-elective; and gestational age coded as $<37$ completed weeks or $\geq 37$ completed weeks. We considered elective CS proxy for CS before labour, reflecting the practice at the facility. Gestational age was calculated according to the last menstrual period (LMP) registered on the antenatal card. For the $10 \%$ with missing LMP, birth weight $\geq 2,500 \mathrm{~g}$ was used as proxy for gestational age $\geq 37$ weeks [21]. Information on the other variables necessary to complete the Ten-Group Classification System was missing in less than 1\% of the sample.

Additional variables used to characterize the sample were: maternal age in years coded as $<20,20-24,25-29$, 30-35 or $>35$; parity coded as $0,1-4$ or $\geq 5$; maternal education coded as none, primary (1-7 years), secondary (8-11 years) or higher ( $\geq 12$ years); and current residence coded as rural, urban or semi-urban. Missing data were less than $1 \%$. We selected medical characteristics known 
to be associated with adverse pregnancy outcome: female genital mutilation (FMG) coded as any type or none; HIV testing coded as recorded or not recorded, HIV status of those recorded coded as positive or negative; antenatal visits coded as 1-3 or $\geq 4$; serious maternal morbidity (preeclampsia, eclampsia, abruptio placentae and placenta praevia) coded as yes or no; and low birth weight of $<2,500$ g coded as yes or no.

We categorized the main admission diagnosis recorded among women delivered by CS. For formally-referred birthing women, this was the referral diagnosis, whilst for self-referred women the receiving midwife noted the main reason for arrival.

\section{Outcome variables}

Selected maternal outcomes were maternal death, prolonged maternal hospital stay as proxy for maternal complications ( $>9$ days after day of delivery $=97.5$ percentile) and major obstetric haemorrhage at delivery $(\geq 750 \mathrm{~mL})$. Data on haemorrhage by clinical estimation were available from 2005 onwards. Due to the high prevalence of anaemia among pregnant women in the area, we chose a cutoff of $750 \mathrm{~mL}$ as a clinically relevant level of obstetric haemorrhage [22]. Neonatal outcomes were neonatal death (excluding intrauterine death diagnosed before labour), low Apgar score ( $<7$ at 5 minutes) and postnatal transfer to the neonatal ward. We excluded cases with missing variables such as delivery mode or presentation (2\%). The final sample included 20,662 births and 21,255 infants with complete information to enable classification using the Ten-Group Classification System.

\section{Referral classification}

Women were categorized as formally-referred when they were referred by qualified health personnel from other hospitals or health facilities such as health centres or dispensaries. The criteria for referral of women for hospital delivery from other health facilities in Tanzania can be found in Table 1 . Women who came directly to KCMC, bypassing referring facilities, were categorized as selfreferred birthing women. The hospital charges these women an extra registration fee. Women delivered by CS in a previous pregnancy are routinely asked to register at $\mathrm{KCMC}$ for the next birth. These women were categorized as self-referred if not referred for other (medical or obstetric) reasons. Self-referred birthing women thus constituted a case mix of women with a wish to deliver in the facility (and able to pay), women directly seeking emergency assistance for obstetric complications bypassing referral facilities for whatever reason and women recommended for delivery at KCMC due to uterine scar(s) but without other obstetric complications. The hospital provides emergency transport for referrals between the regional birth centre (Mawenzi) and KCMC. From other facilities, transport was not regularly available. There were no community-based referral systems in place during the period. Missing referral status applied to $9.4 \%$ of the women. Demographic and obstetric characteristics and pregnancy outcomes for the missing cases were near identical to the total sample average (data not shown). These cases $(n=1950)$ were excluded from the outcome analysis.

\section{Details of ethics approval}

Permission to conduct the study was granted by the National Institute for Medical Research of the Ministry of Health in Tanzania, and the ethics committee at KCMC Hospital. Approval date 2003, reg. NIMR/HQ/R: $\mathrm{Sa} /$ Vol. IX/126.

\section{Statistical analysis}

We extracted and analyzed data with Statistical Package for the Social Sciences/Predictive Analytics Software (SPSS/ $P A S W)$ version 16.0. We used the $\chi^{2}$ test to determine trends in the proportion of CS and formally-referred birthing women during the period, and also to determine crude associations between referral status in CS deliveries and maternal/neonatal outcomes such as maternal/neonatal death, prolonged hospitalisation, obstetric haemorrhage, low Apgar score and transfer to the neonatal ward. Crude odds ratios (cOR) with corresponding 95\% confidence intervals were estimated. We used a one-step multiple binary logistic regression framework to adjust the odds ratios and corresponding 95\% confidence intervals for significant potential confounders such as type of CS, urban/rural residence, parity and low birth weight as proxy for preterm delivery. We considered significance level (p-value) below 0.05 statistically significant.

\section{Results}

\section{Characteristics of the study population}

Table 2 presents demographic, medical and outcome characteristics for the final sample of 20,662 women and 21,255 newborns. Multiple gestations comprised $2.9 \%$ of all deliveries. Of all women, $19 \%(\mathrm{~N}=4,004)$ were formally referred. Among formally-referred birthing women, the majority $(52 \%)$ came from the regional birth centre (Mawenzi) $3 \mathrm{~km}$ away. Demographic characteristics showed that the proportion of teenage mothers (13-19 years) was higher among formally-referred than selfreferred birthing women (15.0\% versus $8.5 \%)$. Formallyreferred women were more frequently rural residents and had lower educational attainments than self-referred women (Table 2). A history of FGM, a diagnosis of serious maternal morbidity and unknown HIV status were also more prevalent among formally-referred women. As expected, formally-referred women had a higher rate of adverse outcomes such as low birth weight babies, maternal death, neonatal death, low Apgar score and transfer to 
Table 1 Criteria for referral from health facility to hospital-level delivery, Tz†

\begin{tabular}{ll}
\hline Elective referral & Emergency intrapartum referral \\
\hline More than 4 pregnancies & Spontaneous rupture of membranes without labour \\
Height $<150 \mathrm{~cm}$ & Labour $<34$ weeks \\
Pelvic deformity & Labour $>12$ hours \\
First pregnancy at 35 or more years & Abnormal lie or presentation of baby \\
Previous Caesarean section or vacuum delivery & Vaginal bleeding \\
Previous postpartum haemorrhage & Abnormal foetal heart $(<120$ or $>160)$ \\
Previous retained placenta & Elevated body temperature $(>38$ degrees Centigrade) \\
Blood pressure $>=140 / 90 \mathrm{~mm} \mathrm{Hg}$ & Eclampsia or blood pressure $>=140 / 90$ mm Hg \\
Hb $<8.5$ gm/dL & Hb $<8.5$ gm/dL \\
Albuminuria & Small pelvis or big baby \\
Glucosuria & Meconium-stained amnion fluid \\
Gestational age $>40$ weeks & \\
Intrauterine foetal death & \\
Abnormal lie (> $>36$ weeks) & \\
Oedema of legs, face and hands & \\
Suspected multiple gestation & \\
Fundal height not corresponding to gestational age & \\
Presence of danger signs* &
\end{tabular}

† According to the Reproductive and Child Health Card (RCHC-4), Ministry of Health, Tanzania. *As defined in the RCHC-4

Table 2 Characteristics of 20,662 women/21,255 infants at KCMC, Tz, 2000-07

\begin{tabular}{|c|c|c|c|c|c|c|}
\hline \multirow[b]{3}{*}{ Factors } & \multicolumn{2}{|c|}{ All births } & \multicolumn{2}{|r|}{ Referred } & \multicolumn{2}{|c|}{ Self-referred } \\
\hline & \multicolumn{2}{|c|}{$\mathrm{N}=20,662 / 21,255$} & \multicolumn{2}{|c|}{$N=4,004 / 4,150$} & \multicolumn{2}{|c|}{$N=14,708 / 15,041$} \\
\hline & $\%$ & CS rate & $\%$ & CS rate & $\%$ & CS rate \\
\hline \multicolumn{7}{|l|}{ †Age, years (median 27) } \\
\hline$<20$ & 9.6 & 29.7 & 15.0 & 45.7 & 8.5 & 22.2 \\
\hline $20-24$ & 27.2 & 30.2 & 27.9 & 53.2 & 27.6 & 23.9 \\
\hline $25-29$ & 28.7 & 33.0 & 23.8 & 59.3 & 30.0 & 27.4 \\
\hline $30-35$ & 24.3 & 35.3 & 22.0 & 58.7 & 24.5 & 29.9 \\
\hline$>35$ & 10.1 & 35.6 & 11.4 & 55.5 & 9.4 & 30.6 \\
\hline \multicolumn{7}{|c|}{ †Parity (mean 1.3, median 1 ) } \\
\hline 0 & 38.5 & 28.9 & 40.3 & 48.8 & 39.0 & 23.1 \\
\hline $1-4$ & 58.1 & 35.6 & 55.0 & 60.4 & 58.2 & 29.7 \\
\hline$>=5$ & 3.4 & 28.7 & 4.7 & 46.0 & 2.8 & 21.8 \\
\hline \multicolumn{7}{|l|}{ Maternal education } \\
\hline None & 2.2 & 45.2 & 4.2 & 58.7 & 1.7 & 35.7 \\
\hline Primary (1-7) & 64.8 & 34.7 & 77.9 & 55.2 & 61.5 & 28.0 \\
\hline Secondary (8-11) & 4.7 & 29.0 & 3.9 & 53.8 & 4.9 & 24.9 \\
\hline Higher (12+) & 28.0 & 27.8 & 14.0 & 53.7 & 31.9 & 24.6 \\
\hline \multicolumn{7}{|l|}{ †Current residence } \\
\hline Rural & 46.2 & 38.1 & 67.2 & 53.4 & 40.2 & 31.9 \\
\hline Urban & 49.3 & 27.4 & 27.9 & 57.9 & 55.3 & 23.1 \\
\hline Semi urban & 4.5 & 36.3 & 4.9 & 60.7 & 4.5 & 29.6 \\
\hline \multicolumn{7}{|c|}{ Female Genital Mutilation } \\
\hline FGM, any type & 25.2 & 36.5 & 32.4 & 55.9 & 23.0 & 29.5 \\
\hline No FGM & 74.8 & 31.5 & 67.6 & 54.7 & 77.0 & 26.2 \\
\hline \multicolumn{7}{|l|}{ HIV status } \\
\hline tHIV test recorded & 47.9 & 31.8 & 39.6 & 50.4 & 52.7 & 28.1 \\
\hline HIV + (of recorded) & 6.4 & 32.4 & 7.3 & 44.8 & 6.3 & 29.5 \\
\hline \multicolumn{7}{|l|}{ Antenatal care } \\
\hline One visit or more & 99.2 & 32.7 & 99.2 & 55.1 & 99.3 & 26.9 \\
\hline
\end{tabular}


Table 2 Characteristics of 20,662 women/21,255 infants at KCMC, Tz, 2000-07 (Continued)

\begin{tabular}{|c|c|c|c|c|c|c|}
\hline 4 visits or more & 75.5 & 32.1 & 60.2 & 55.5 & 76.5 & 26.7 \\
\hline \multicolumn{7}{|c|}{ †Serious mat. morbidity* } \\
\hline Yes & 5.4 & 47.9 & 8.6 & 56.5 & 4.4 & 43.2 \\
\hline No & 94.6 & 31.9 & 91.4 & 54.9 & 95.6 & 26.2 \\
\hline \multicolumn{7}{|l|}{ †Low birth weight (g) } \\
\hline$<2500$ & 13.1 & 32.2 & 18.5 & 49.4 & 11.6 & 33.6 \\
\hline$>=2500$ & 86.9 & 38.6 & 81.5 & 56.1 & 88.4 & 26.4 \\
\hline \multicolumn{7}{|l|}{ Outcomes } \\
\hline \multicolumn{7}{|l|}{ †Haemorrhage ${ }^{* *}$} \\
\hline$>=750 \mathrm{cc}$ & 2.3 & 81.3 & 3.5 & 83.3 & 2.0 & 80.4 \\
\hline$<750 \mathrm{cc}$ & 97.7 & 31.3 & 96.5 & 47.9 & 98.0 & 26.6 \\
\hline \multicolumn{7}{|l|}{ †Postpartum stay } \\
\hline$>9$ days & 2.1 & 57.0 & 3.6 & 69.9 & 1.8 & 50.2 \\
\hline$<=9$ days & 97.9 & 31.7 & 96.4 & 54.3 & 98.2 & 26.0 \\
\hline \multicolumn{7}{|l|}{ †Maternal death } \\
\hline Yes & 0.1 & 40.7 & 0.2 & 37.5 & 0.1 & 44.4 \\
\hline No & 99.9 & 32.7 & 99.8 & 54.9 & 99.9 & 26.9 \\
\hline \multicolumn{7}{|l|}{ †Apgar score } \\
\hline Apgar $<7$ at $5^{\prime \prime}$ & 2.7 & 48.8 & 5.1 & 57.8 & 2.1 & 42.9 \\
\hline Apgar $>=7$ at $5^{\prime \prime}$ & 97.3 & 32.7 & 94.9 & 55.3 & 97.7 & 27.0 \\
\hline \multicolumn{7}{|l|}{ †Neonatal death } \\
\hline Yes & 1.0 & 44.0 & 1.9 & 46.8 & 0.7 & 43.1 \\
\hline No & 99.0 & 32.8 & 98.1 & 54.9 & 99.3 & 27.0 \\
\hline \multicolumn{7}{|c|}{$\dagger$ Transfer to neonatal ward } \\
\hline Yes & 14.2 & 21.8 & 21.5 & 61.9 & 12.2 & 45.3 \\
\hline No & 85.8 & 10.5 & 78.5 & 52.7 & 87.8 & 24.6 \\
\hline
\end{tabular}

†Associated to referral status $(\mathrm{P}<.01$; Chi-Square). *Including hypertensive disorders in pregnancy including preeclampsia, abruptio placentae and placenta praevia. ${ }^{* *}$ Data available for 2005 and onwards.

the neonatal ward (Table 2). For other variables, there were no apparent major differences in characteristics according to referral status.

Twenty-seven maternal deaths were recorded in the final sample, equivalent to a maternal mortality ratio (MMR) of 131/100,000 births. This does not reflect the true facility-based MMR, as deaths in early pregnancy, in other departments or postpartum were not routinely recorded in the registry. For all births the perinatal mortality rate was $44 / 1,000$, of which stillborn rate was 38 / 1000 (44\% fresh) and early (facility-based) neonatal death rate was $6 / 1,000$, thus less than $1 \%$. Only deaths occurring in the facility were included in the registry.

\section{Caesarean section rates in referred and self-referred birthing women}

In the final sample, 6,765 women were delivered by CS; a facility-based CS rate of $32.7 \%$. Emergency CS constituted $80 \%$ of all CS deliveries. Less than $2 \%$ of all births were operative vaginal births (ventouse or forceps). CS rates rose from $28.5 \%$ in year 2000 to $35.5 \%$ in 2004 , thereafter falling slightly to $31.7 \%$ in 2006 (Figure 1). Overall, there was a significant increase in CS rates over the study period $\left(\chi^{2}\right.$ for trend, $\left.p<0.01\right)$. The proportion of formally-referred birthing women remained unchanged over the period ( $\chi^{2}$ for trend, $p=0.26$ ).

Table 3 presents CS rates in the ten groups, sizes of the groups and their relative contributions to the overall rate

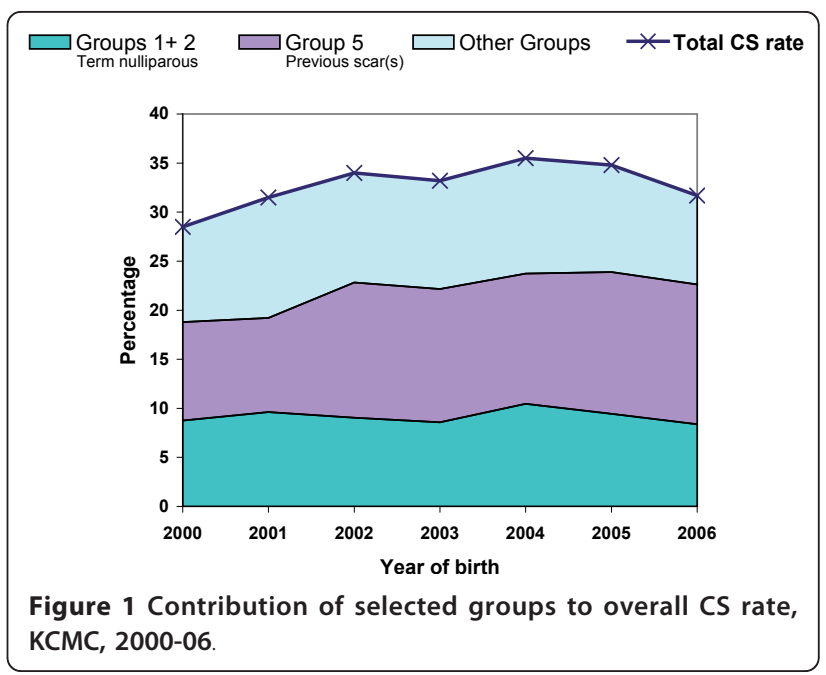


Table 3 Caesarean section rates 2000-07 according to the Ten-Group Classification and referral status, KCMC, Tz

\begin{tabular}{|c|c|c|c|c|c|c|c|c|}
\hline \multirow[b]{2}{*}{ Ten-Groups } & \multirow[b]{2}{*}{$\mathbf{N}$} & \multirow[b]{2}{*}{ Referred } & \multicolumn{2}{|c|}{ Total CS rate $(\%)$} & \multicolumn{2}{|c|}{ Contrib. rate (\%) } & \multicolumn{2}{|c|}{ Size of group (\%) } \\
\hline & & & Self-refer. & $P^{*}$ & Referred & Self-refer. & Referred & Self-refer. \\
\hline 1. Nulliparous, single ceph., $>=37$ w, sp. labour & 4,001 & 58.4 & 20.3 & $<.01$ & 11.7 & 4.0 & 20.0 & 19.7 \\
\hline 2. Nulliparous, single ceph., $>=37 \mathrm{~W}$, induced/CS & 2,877 & 32.9 & 24.5 & $<.01$ & 4.2 & 3.6 & 12.8 & 14.6 \\
\hline 3. Multiparous, single, ceph., $>=37$ w, sp. labour & 5,006 & 41.4 & 8.7 & $<.01$ & 6.3 & 2.3 & 15.3 & 26.0 \\
\hline 4. Multiparous, single, ceph., $>=37 \mathrm{w}$, induced/CS & 2,079 & 32.5 & 15.7 & $<.01$ & 2.2 & 1.7 & 6.8 & 10.7 \\
\hline 5. Previous CS, single ceph., $>=37 \mathrm{~W}$ & 3,556 & 82.6 & 69.7 & $<.01$ & 19.3 & 10.8 & 23.4 & 15.5 \\
\hline 6. Nulliparous breeches & 135 & 74.4 & 65.9 & .33 & 0.8 & 0.4 & 1.1 & 0.6 \\
\hline 7. Multiparous breeches (incl. previous CS) & 205 & 57.7 & 35.2 & $<.01$ & 0.8 & 0.3 & 1.3 & 0.8 \\
\hline 8. Multiple pregnancies (incl. previous CS) & 589 & 46.4 & 36.8 & .04 & 1.9 & 0.9 & 4.2 & 2.5 \\
\hline 9. Abnormal lies (incl. previous CS) & 60 & 93.1 & 85.7 & .64 & 0.7 & 0.1 & 0.7 & 0.1 \\
\hline 10. Single, ceph., $<=36 \mathrm{w}$ (incl. previous CS) & 2,154 & 49.5 & 30.3 & $<.01$ & 7.1 & 2.8 & 14.3 & 9.4 \\
\hline Total & 20,662 & 55.0 & 26.9 & $<.001$ & 55.0 & 26.9 & 99.9 & 99.9 \\
\hline
\end{tabular}

*Chi-squared/Fisher's Exact tests.

for all births and by referral status. The proportion of CS was higher overall in the formally-referred group than in the self-referred group, $55 \%$ versus $27 \%$ (cOR 3.32, 95\% CI 3.09-3.57, $p<0.001$ ). Emergency CS was more frequent in the formally-referred than in the self-referred group, 85\% versus $79 \%$ (cOR 1.50, 95\% CI 1.30-1.72, $p<0.01$ ). Elective CS rates were low in general, except in group 5 (previous scar) with singleton cephalic presentation) where both formally-referred and self-referred birthing women had rates $>20 \%$ (data not shown). For both referral categories women with previous scar(s) (group 5) and term singleton cephalic nulliparous women (groups $1+2$ ) contributed most towards the total CS rate. These three groups comprised $66 \%$ of all CS in the facility (Figure 1).

\section{Main admission diagnoses by referral status}

Table 4 presents the main admission diagnoses by referral status for the 6,161 CS deliveries, as recorded in the registry. "Previous scar(s)" and "obstructed labour" were the most frequent registered diagnoses in both groups. In formally-referred birthing women these were followed by "cephalo-pelvic disproportion" and "poor progress," whilst in self-referred birthing women, these were followed by "poor progress" and "foetal distress."

\section{Associations between referral status and post-Caesarean section maternal and neonatal outcomes}

Table 5 presents the effect of referral status on cOR and adjusted odds ratio (aOR) for six maternal and neonatal outcomes after CS. By univariate analyses, neither maternal death $(\mathrm{N}=7, \mathrm{cOR} 1.35,95 \% \mathrm{CI} 0.30-6.06, p=$ 0.71 ) nor obstetric haemorrhage (cOR $1.05,95 \%$ CI $0.73-1.52, p=0.78$ ) was associated with referral status. Prolonged postpartum stay was associated with formally-referred status (cOR 1.38, 95\% CI 1.05-1.81, $p=$ 0.02 ), but this effect did not remain significant after adjusting for potential confounders such as parity, type of CS, preterm birth and residence.

Analysis of neonatal outcomes after CS did not find any association between formal referral and neonatal death (aOR 1.37, 95\% CI 0.87-2.16). Both low Apgar score (aOR 1.42, 95\% CI 1.09-1.86, $p<0.01$ ) and transfer to the neonatal ward (aOR 1.18, 95\% CI 1.04-1.35, $p<0.01$ ) were associated with formal referral after adjusting for parity, low birth weight, type of CS and residence. Maternal age was not associated with the outcomes by univariate analysis and was not included as an adjusting factor.

\section{Outcomes after Caesarean section by referral status in the Ten-Group Classification System}

Tables A1 and A2 (Additional file 1) show the distribution of adverse maternal and perinatal outcomes in CS deliveries according to The Ten-Group Classification System. The absolute number of cases per group is small, and data must be interpreted with caution. Obstetric haemorrhage occurred in one out of ten preterm CS deliveries (group 10), and was also prevalent in other obstetric high-risk groups (groups 6-9). Neonatal death rates were $>2 \%$ in group 3 (multiparous, spontaneous labour), groups 6 and 7 (breech), group 8 (multiple gestation) and group 10 (preterm singleton cephalic). Frequency of low Apgar score was $>7 \%$ in groups 6 and 7 (breech), group 9 (malpresentation) and group 10 (preterm). Among formally-referred CS, low Apgar score was prevalent in groups 6 and 7 (breech) and group 10 (preterm). Among self-referred CS, low Apgar score was most prevalent in group 10 (preterm). Transfer to the neonatal ward occurred in one out of four formally-referred births, compared with one out of five self-referred births. Both formally-referred and selfreferred births in group 5 (previous scar) had low 
Table 4 Main admission diagnosis recorded among 6,161 Caesarean births, KCMC, Tz

\begin{tabular}{|c|c|c|c|c|}
\hline \multirow[t]{2}{*}{ Diagnosis } & \multicolumn{2}{|c|}{ Referred $(\mathrm{N}=2,203)$} & \multicolumn{2}{|c|}{ Self-referred $(\mathrm{N}=3,958)$} \\
\hline & $\mathrm{N}$ & $\%$ & $\mathrm{~N}$ & $\%$ \\
\hline 1 previous scar $+/$ - other obstetric diagnosis & 430 & 19.5 & 469 & 11.8 \\
\hline 2 previous scars $+/$ - other obstetric diagnosis & 222 & 10.1 & 186 & 4.7 \\
\hline $3+$ previous scars $+/$ - other obstetric diagnosis & 47 & 2.1 & 29 & 0.7 \\
\hline Abruptio & 33 & 1.5 & 23 & 0.6 \\
\hline Anaemia/haematologic disorder & 24 & 1.1 & 2 & 0.1 \\
\hline Ante partum haemorrhage & 47 & 2.1 & 18 & 0.5 \\
\hline Bad obstetric history & 29 & 1.3 & 23 & 0.6 \\
\hline Breech & 52 & 2.4 & 70 & 1.8 \\
\hline Cephalo-pelvic disproportion & 202 & 9.2 & 78 & 2.0 \\
\hline Eclampsia & 53 & 2.4 & 27 & 0.7 \\
\hline Failure of trial of scar/induction & 14 & 0.6 & 57 & 1.4 \\
\hline Foetal distress & 123 & 5.6 & 155 & 3.9 \\
\hline Hypertension & 31 & 1.4 & 20 & 0.5 \\
\hline Malpresentation/prolapse arm/cord & 119 & 5.4 & 60 & 1.5 \\
\hline Multiple pregnancy & 29 & 1.3 & 24 & 0.6 \\
\hline Obstructed labour & 236 & 10.7 & 175 & 4.4 \\
\hline Placenta previa & 36 & 1.6 & 23 & 0.6 \\
\hline Poor progress/prolonged labour & 192 & 8.7 & 165 & 4.2 \\
\hline Post term & 7 & 0.3 & 17 & 0.4 \\
\hline Preeclampsia & 74 & 3.4 & 28 & 0.7 \\
\hline Preterm rupture membranes/preterm labour & 30 & 1.4 & 42 & 1.1 \\
\hline Uterine rupture & 8 & 0.4 & 6 & 0.2 \\
\hline Expected vaginal delivery & 6 & 0.3 & 282 & 7.1 \\
\hline No diagnosis & 121 & 5.5 & 1953 & 49.3 \\
\hline Other + & 38 & 1.7 & 26 & 0.7 \\
\hline Total & 2,203 & 100 & 3,958 & 100 \\
\hline
\end{tabular}

†'Other' included maternal risk factor, diabetes, heart disease, cardiac arrest, HAART, PPH, chorio chorioamnionitis, IUFD, vaginal warts, malformation baby, repaired fistula, diarrhoea, pelvic mass, IUGR, cervix cancer, difficult labour, mental disease, physical handicap, fracture.

frequencies of obstetric haemorrhage, neonatal death and low Apgar score.

\section{Analysis of results before and after introduction of cost-} sharing

Due to the gradual introduction of cost-sharing from 2005 (during the period under study), we compared results from before and after January 1st 2005.
There was no difference in the proportion of formallyreferred birthing women between the time periods ( $21.5 \%$ versus $21.1 \%, \mathrm{p}<0.57)$. Formally-referred women were significantly younger, with a lower level of education and a higher proportion of rural residents in the second time period compared with the first. Self-referred women on the contrary were significantly older, had better educational attainments and a lower proportion of

Table 5 Associations between referral status and pregnancy outcomes in Caesarean births, KCMC, Tz

\begin{tabular}{|c|c|c|c|c|c|c|c|c|c|c|c|c|}
\hline \multirow[b]{2}{*}{ Maternal outcomes } & \multicolumn{2}{|c|}{ All CS } & \multicolumn{2}{|c|}{ Referred } & \multicolumn{2}{|c|}{ Self-ref. } & \multirow[t]{2}{*}{ COR } & \multirow[t]{2}{*}{$\mathrm{Cl}$ for $\mathrm{cOR}$} & \multirow[t]{2}{*}{$P$} & \multirow[t]{2}{*}{$\mathrm{aOR}+$} & \multirow[t]{2}{*}{$\mathrm{Cl}$ for aORt } & \multirow[t]{2}{*}{$\mathrm{aPt}$} \\
\hline & $\mathrm{N}$ & $\%$ & $\mathrm{~N}$ & $\%$ & $\mathrm{~N}$ & $\%$ & & & & & & \\
\hline Maternal death & 7 & 0.1 & 3 & 0.1 & 4 & 0.1 & 1.35 & $0.30-6.06$ & .71 & $\mathrm{NI}$ & & \\
\hline Haemorrhage ${ }^{*}$ & 135 & 5.8 & 45 & 6.0 & 90 & 5.7 & 1.05 & $0.73-1.52$ & .78 & $\mathrm{NI}$ & & \\
\hline Prolonged stay & 220 & 3.8 & 95 & 4.5 & 125 & 3.3 & 1.38 & $1.05-1.81$ & .02 & 1.22 & $0.92-1.61$ & .17 \\
\hline \multicolumn{13}{|l|}{ Neonatal outcomes } \\
\hline Neonatal death & 83 & 1.3 & 36 & 1.6 & 47 & 1.2 & 1.39 & $0.90-2.16$ & .14 & 1.37 & $0.87-2.16$ & .17 \\
\hline Low Apgar & 250 & 4.0 & 118 & 5.3 & 132 & 3.3 & 1.65 & $1.28-2.13$ & .00 & 1.42 & $1.09-1.86$ & .01 \\
\hline Transfer neonatal ward & 1388 & 21.9 & 553 & 24.4 & 835 & 20.5 & 1.25 & $1.11-1.41$ & .00 & 1.18 & $1.04-1.35$ & .01 \\
\hline
\end{tabular}

†Adjusted for parity, low birth weight, type of CS, residence. *Data from 2005 onwards. $\mathrm{NI}=$ Not included in multiple regression analysis. 
rural residents in the second time period. In both groups the proportion with four or more antenatal visits decreased significantly between the first time period and the second.

The overall CS rate among formally-referred birthing women fell from $58.8 \%$ to $49.2 \%$ between the first time period and the second (OR 0.68, CI 0.60-0.78, p < 0.001 ), whilst the rate among self-referred women remained unchanged. The main reasons for referral were the same for the two time periods. For CS births, only neonatal death showed a crude association with the time period, with an increase of overall neonatal deaths from $0.9 \%$ to $1.2 \%(\mathrm{p}<0.03)$ between the first time period and the second. Adding time period as an explanatory variable in the regression models did not impact on the adjusted estimates.

\section{Discussion}

Based on registry data from 21,000 hospital-based births at a tertiary care centre in northeastern Tanzania, we found that $80 \%$ of birthing women were self-referred and only $20 \%$ were formally referred through the national referral system. Formal referral was associated with rural residence, less education and a higher obstetric risk profile. As expected, CS rates were higher in formally-referred than self-referred women, but the main contributing groups (women with previous CS and nulliparous women) were the same regardless of referral status. Overall there was a high repeat CS rate and a low prevalence of operative vaginal delivery, both of which affect utilization of CS. Low Apgar score and transfer to the neonatal ward were both associated with formal referral for delivery. Poor neonatal outcome rates were high in some subgroups (breech, multiple gestation and preterm birth) of self-referred CS deliveries, pointing to a significant proportion of risk in women that bypass or are not reached by referral systems. Conversely, we found no differences in adverse maternal outcomes after CS in formally-referred versus self-referred birthing women.

In this study, we have shown that basic data, which are already collected in most delivery wards, can be usefully evaluated in a standardised way. The strength of this study lies in the large sample size and completeness of data for the majority of CS deliveries conducted in the area. A small number of CS deliveries performed elsewhere in the area were not included, but the magnitude of their effects on our results would be small. Using registry data imposed limitations on our study. Although validity checks are performed regularly, registry data are likely to be of lesser quality than data specifically collected for research purposes. We did not have direct information from the referring facilities nor referring health staff to be able to assess the compliance, appropriateness and timeliness of referral. We also did not have data regarding community referral processes such as decision-making in the event of an obstetric complication, or information about women that never reached appropriate care. Such data would have added value to the study. Multiple levels of referral and delay in receiving care once in the tertiary care centre could not be assessed, as this information was not included in the registry. Proxy endpoints such as infection parameters or blood transfusion were not part of the registry information. This limited our selection of outcomes. Patient selection played a role as only a proportion of women in Kilimanjaro will reach a tertiary facility in the event of complications. In particular, out-of-pocket fees are likely to be a barrier to seeking care, which is supported by our finding that women giving birth at KCMC have better educational attainments compared with the regional average [6]. Measures of association between referral status and outcome are less likely to be influenced by selection bias.

Interestingly, the groups that contributed the most to overall CS rates were the same in formally-referred and self-referred women. Comparing with Ten-Group Classification System data from the US and Europe, we found similar CS rates in groups $1+2$ (term singleton cephalic nulliparous women), and in contributions of groups $1+2$ +5 to the total rate [23]. Similarly, we found that the high CS rate in term singleton cephalic nulliparous women contributes to a high overall CS rate, similar to highresource contexts [23]. We also found dissimilarities, such as high CS rates among self-referred women in groups 1 and 3 (spontaneous labour) compared with groups 2 and 4 (induced or elective CS before labour) in our setting compared with high-resource contexts. This suggests a failure to detect obstetric morbidity at antenatal care for induction or planned CS, allowing high-risk cases to proceed into labour. Group 5 (previous scar) was responsible for $40 \%$ of CS cases in self-referred women. We believe the high repeat CS rate in this group of $70 \%$ was affected by a shortage of attempts at trial of labour due to lack of human and material resources. By definition, this subgroup had no other registered obstetric complication, explaining the favourable fetal outcomes following CS. Use of ventouse or forceps was not part of the resident training programme in this facility, which will increase CS rates in most obstetric groups, compared with other settings.

Although not directly comparable, the hospital-based early perinatal mortality rate was high (4.4\%) compared with high-resource settings where population-based perinatal mortality rate is often as low as $0.5 \%$ [24]. The early (hospital-based) neonatal mortality rate in babies born by CS of $1.3 \%$ in this facility reflects not only obstetric conditions, but also lack of advanced intensive care neonatal services. Investigation of differences between subgroups within the self-referred population showed that group 5 
(previous scar) had low rates of all adverse neonatal outcomes, indicating that these risks lie within other obstetric groups. The surprising finding that adverse maternal outcomes were not related to referral status is likely due to the proximity of the main referring facility with provision of emergency transport. Thus mothers that make it to the referral centre receive CS in time to save their lives. Although we do show that rural and otherwise disadvantaged women have some degree of access to referral, the low absolute number of referrals from rural facilities confirms a disappointing underuse of CS for rural Tanzanian women [13]. Among self-referred women, women with no education and with rural residence had the highest CS rates, strongly suggesting the need to target this subgroup for earlier professional care and referral. Jahn et al. identified substandard antenatal care and lack of community trust in lower level health providers as contributing factors to self-referral in southern Tanzania [25]. After the introduction of user fees, we found a less favourable sociodemographic profile in formally-referred women, whilst the opposite was the case for self-referred women. A selection bias towards referral of poor women that are eligible for exemption from fees could explain these findings. We found that the proportion of women accessing the recommended four antenatal visits decreased between the first time period and the second. Reversing this trend is necessary to improve third trimester detection of increased risk conditions with poor outcomes such as breech, multiple gestation and threatened preterm labour, thus assuring earlier referral for optimal care. We still need more operational knowledge of utilization of services by women and babies at risk to expand equitable access.

To better evaluate the effects of reproductive health programs, we would advocate for the expansion of facility registers to regional-based birth registries. This would give better return on investment than single registers in a situation where a countrywide population-based health information system is not yet feasible. The Ten-Group Classification System is widely used in high-resource settings, but so far less used in low-resource settings. This could be due to limited resources available for systematic CS audits. We believe it offers a standardized tool that, combined with knowledge of local obstetric epidemiology, is useful in the continuous evaluation of regional obstetric care and hence promotion of quality and equity.

\section{Conclusions}

Women formally referred for delivery constituted a low proportion of all births, but contributed substantially to CS rates and adverse outcomes, indicating that the referral system does identify high-risk women. Nevertheless, subgroups within the larger population of self-referred women showed poor neonatal outcomes in absolute terms, suggesting a dire lack of timely identification.
Strategies to improve neonatal outcomes after CS deliveries must strengthen both the existing referral system and cater to subgroups of self-referred births not caught by the present system. Targeted interventions should be directed towards improving the continuum of care for obstetric risk groups, especially multiple gestation, breech and preterm births. To be able to promote rational delivery of care and evaluate the effectiveness of operational interventions in this context, regional information gathering systems would provide a much better return on investment than single facility-based registers.

\section{Additional material}

Additional file 1: Tables A1 and A2. Table A1. Ten-Group Classification versus maternal outcomes in 6,161 Caesarean sections. with known referral status, KCMC, Tz. Table A2. Ten-Group Classification versus neonatal outcomes in 6,388 Caesarean births, with known referral status, KCMC, Tz.

\section{Acknowledgements and Funding}

The authors gratefully acknowledge the participation of mothers who contributed information and time towards the birth registry. We also want to thank the medical, administrative and management staff at KCMC who made this study possible, especially the contributions and comments of the late Dr. Rowland Lyatuu.

A PhD research grant from the National Resource Centre for Women's Health, Oslo University Hospital HF, Rikshospitalet, Oslo, Norway, funded the study.

\section{Author details}

${ }^{1}$ National Resource Centre for Women's Health, Department of Obstetrics and Gynaecology, Oslo University Hospital HF, Rikshospitalet, Oslo, Norway. ${ }^{2}$ Norwegian Institute of Public Health, Oslo, Norway. ${ }^{3}$ Kilimanjaro Christian Medical Centre, Department of Obstetrics and Gynaecology, Moshi, Tanzania. ${ }^{4}$ Institute of Health and Society, Department of International Community Health, University of Oslo, Norway.

\section{Authors' contributions}

IKS, SV and PB conceived of the study and participated in its design. IS conducted the statistical analyses and drafted the manuscript in collaboration with SV. OO participated in design of the study, interpretation of data and coordination of the work. All authors read and commented on drafts of the manuscript. All authors except PB approved the final manuscript.

\section{Competing interests}

The authors declare that they have no competing interests.

Received: 4 March 2011 Accepted: 28 July 2011 Published: 28 July 2011

\section{References}

1. United Nations: The Millennium Development Goals Report 2009. [http:// www.un.org/millenniumgoals/pdf/MDG_Report_2009_ENG.pdf].

2. WHO, The Partnership for Maternal, Newborn and Child Health: Opportunities for Africa's newborns: Practical data, policy and programmatic support for newborn care in Africa. [http://www.who.int/ pmnch/media/publications/oanfullreport.pdf].

3. WHO, The Partnership for Maternal, Newborn and Child Health: The Partnership for Maternal, Newborn and Child Health. [http://www.who. int/pmnch/topics/part_publications/pmnchstrategy2009_2011.pdf].

4. Mcclure EM, Goldenberg RL, Bann CM: Maternal mortality, stillbirth and measures of obstetric care in developing and developed countries. Int J Gynaecol Obstet 2007, 96:139-146. 
5. Kongnyuy EJ, Hofman JJ, van den BN: Ensuring effective Essential Obstetric Care in resource poor settings. BJOG 2009, 116(Suppl 1):41-47.

6. National Bureau of Statistics [Tanzania], Macro International Inc.2006: Tanzania Demographic and Health Survey Final Report Dar Es Salaam, Tanzania; 2004.

7. Hunger C, Kulker R, Kitundu H, Massawe S, Jahn A: Assessing unmet obstetric need in Mtwara Region, Tanzania. Trop Med Int Health 2007 12:1239-1247.

8. Prytherch H, Massawe S, Kuelker R, Hunger C, Mtatifikolo F, Jahn A: The unmet need for emergency obstetric care in Tanga Region, Tanzania. BMC Pregnancy Childbirth 2007, 7:16

9. Editorial: Appropriate technology for birth. Lancet 1985, 2:436-437.

10. National Bureau of Statistics [Tanzania] MoHaSWTaMII2: Tanzania Service Provision Assessment Survey 2006 Dar es Salaam, Tanzania; 2010.

11. Kruk ME, Mbaruku G, McCord CW, Moran M, Rockers PC, Galea S: Bypassing primary care facilities for childbirth: a population-based study in rural Tanzania. Health Policy Plan 2009, 24:279-288.

12. Muganyizi PS, Kidanto HL: Impact of change in maternal age composition on the incidence of Caesarean section and low birth weight: analysis of delivery records at a tertiary hospital in Tanzania, 1999-2005. BMC Pregnancy Childbirth 2009, 9:30.

13. Ronsmans C, Holtz S, Stanton C: Socioeconomic differentials in caesarean rates in developing countries: a retrospective analysis. Lancet 2006, 368:1516-1523.

14. Robson MS: Classification of Caesarean sections. Fetal and Maternal Medicine Review 2001, 12:23-39.

15. Bergsjo P, Mlay J, Lie RT, Lie-Nielsen E, Shao JF: A medical birth registry at Kilimanjaro Christian Medical Centre. East Afr J Public Health 2007, 4:1-4.

16. Moland KM: Giving birth in Kilimanjaro- The politics of knowledge in moral contexts. PhD thesis University of Bergen, Department of Administration and Organisation Theory and Centre for International Health; 2002.

17. Currency rates as of January 1st, 2005. [http://www.oanda.com/currency/ historical-rates].

18. World Bank: Poverty headcount ratio at $\$ 1.25$ a day (PPP) ( $\%$ of population). [http://data.worldbank.org/indicator/SI.POV.DDAY/countries/TZ? display=graph].

19. McCarthy FP, Rigg L, Cady L, Cullinane F: A new way of looking at Caesarean section births. Aust N Z J Obstet Gynaecol 2007, 47:316-320.

20. The National Maternity Hospital DI, Robson MS: Clinical report for the year 2005, Dublin 2006

21. Physical status: the use and interpretation of anthropometry. Report of a WHO Expert Committee. World Health Organ Tech Rep Ser 1995, 854:1-452

22. Bergsjo $\mathrm{P}$, Seha $\mathrm{AM}$, Ole-King'ori $\mathrm{N}$ : Hemoglobin concentration in pregnant women. Experience from Moshi, Tanzania. Acta Obstet Gynecol Scand 1996, 75:241-244.

23. Brennan DJ, Robson MS, Murphy M, O'Herlihy C: Comparative analysis of international cesarean delivery rates using 10-group classification identifies significant variation in spontaneous labor. Am J Obstet Gynecol 2009, 201:308

24. WHO: Health for all database. [http://www.euro.who.int/en/what-we-do/ data-and-evidence/databases/european-health-for-all-database-hfa-db2].

25. Jahn A, Kowalewski M, Kimatta SS: Obstetric care in southern Tanzania: does it reach those in need? Trop Med Int Health 1998, 3:926-932.

\section{Pre-publication history}

The pre-publication history for this paper can be accessed here: http://www.biomedcentral.com/1471-2393/11/55/prepub

doi:10.1186/1471-2393-11-55

Cite this article as: Sørbye et al:: Caesarean section among referred and self-referred birthing women: a cohort study from a tertiary hospital, northeastern Tanzania. BMC Pregnancy and Childbirth 2011 11:55.

\section{Submit your next manuscript to BioMed Central and take full advantage of:}

- Convenient online submission

- Thorough peer review

- No space constraints or color figure charges

- Immediate publication on acceptance

- Inclusion in PubMed, CAS, Scopus and Google Scholar

- Research which is freely available for redistribution

Submit your manuscript at www.biomedcentral.com/submit
C Biomed Central 